\title{
Exercise-Induced Elastofibroma Dorsi
}

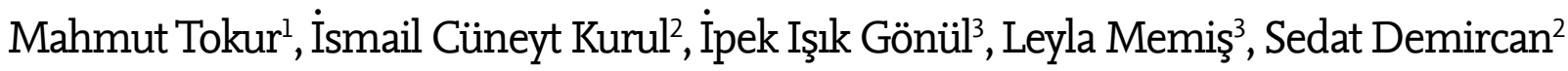

\author{
${ }^{1}$ Department of Thoracic Surgey, Kahramanmaraş Sütçü İmam University Faculty of Medicine, Kahramanmaraş \\ ${ }^{2}$ Department of Thoracic Surgey, Gazi University Faculty of Medicine, Ankara \\ ${ }^{3}$ Department of Pathology, Gazi University Faculty of Medicine, Ankara
}

\begin{abstract}
Elastofibroma dorsi is a rare, slow-growing tumor-like process. It is typically found in the soft tissue compartment between the inferior scapula and the chest wall of an elderly person. Although its findings in magnetic resonance images and computed tomography usually allow a prospective diagnosis, recognizing the benign nature of the lesion with histopathological evaluation is important to avoid radical surgery. Its pathogenesis is unknown, but one of the postulated mechanisms is repetitive mechanical trauma around the shoulder girdle. We report a synchronously diagnosed bilateral elastofibroma excised from the back of a 49-year-old woman who had doing aerobic exercise for a long time.
\end{abstract}

Keywords: Chest wall, elastofibroma dorsi, bilateral, exercise

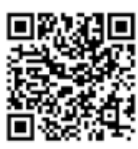

Received date: 01.11 .2011 Accepted date: 18.02.2012

\section{Address for correspondence}

Mahmut Tokur, Department of Thoracic Surgey,

Kahramanmaraş Sütçü İmam University Faculty of

Medicine, Kahramanmaraş, Turkey

E-mail: mahmuttokur@hotmail.com

(C) Copyright 2014 Turkish Respiratory Society (TRS) DOI: 10.5152/ejp.2014.78055

• Available online at www.eurasianjpulmonol.com

\section{INTRODUCTION}

Elastofibroma dorsi (EFD) is a slow, soft-growing tissue lesion of the chest wall, and its characteristics are sometimes difficult to identify, since it is rare (1). The first four cases were described by Jarvi and Saxen (2) in 1961 as tumors originating from elastic tissue. Since then, only a limited number of bilateral synchronous cases have been added to the literature (3-5).

Most cases were reported in the elderly, with women affected more often than men (1). But, younger patients, including children, were also reported in recent years (6). The lesion is most often situated between the scapula and chest wall, but various sites, including forefoot, greater omentum, stomach, mediastinum, axilla, ischium, rectum, breast, hands, and feet, were also reported for its presence $(3,6)$. It is unilateral in the majority of cases, and the frequency of bilateral occurrence has been reported to be between $10-66 \%$ $(3,6)$. Histopathologically, it is composed of fibroblasts, vascular structures, fat, collagen, and elastic fibers. The elastic fibers usually have a characteristic beaded appearance or are fragmented into small globules.

We report a case of bilateral synchronous EFD with its radiologic, clinical, and histopathological findings.

\section{CASE PRESENTATION}

A 49-year-old woman was referred to our clinic for evaluation of a palpable mass located in her right infrascapular area. She first recognized the mass incidentally while taking a shower about 3 months before admission. She had no complaints other than prominent progressive enlargement of the lesion. The patient has a history of doing aerobic exercise for a long time.

Physical examination revealed a firm, palpable mass located in the right infrascapular area. It was approximately $10 \times 8 \mathrm{~cm}$ in diameter, and it flipped out into view on flexion of the pectoral girdle at the inferior tip of the scapula. Another small, non-tender mass measuring about $6 \times 4 \mathrm{~cm}$ located in the left subscapular area was also palpated, but the patient did not recognize this one. Laboratory data were within the normal limits.

Chest roentgenogram presumed an extrathoracic mass located under the right scapular region (Figure 1a). Thorax magnetic resonance imaging (MRI) revealed a sharp marginated, circumscribed, heteroge- 


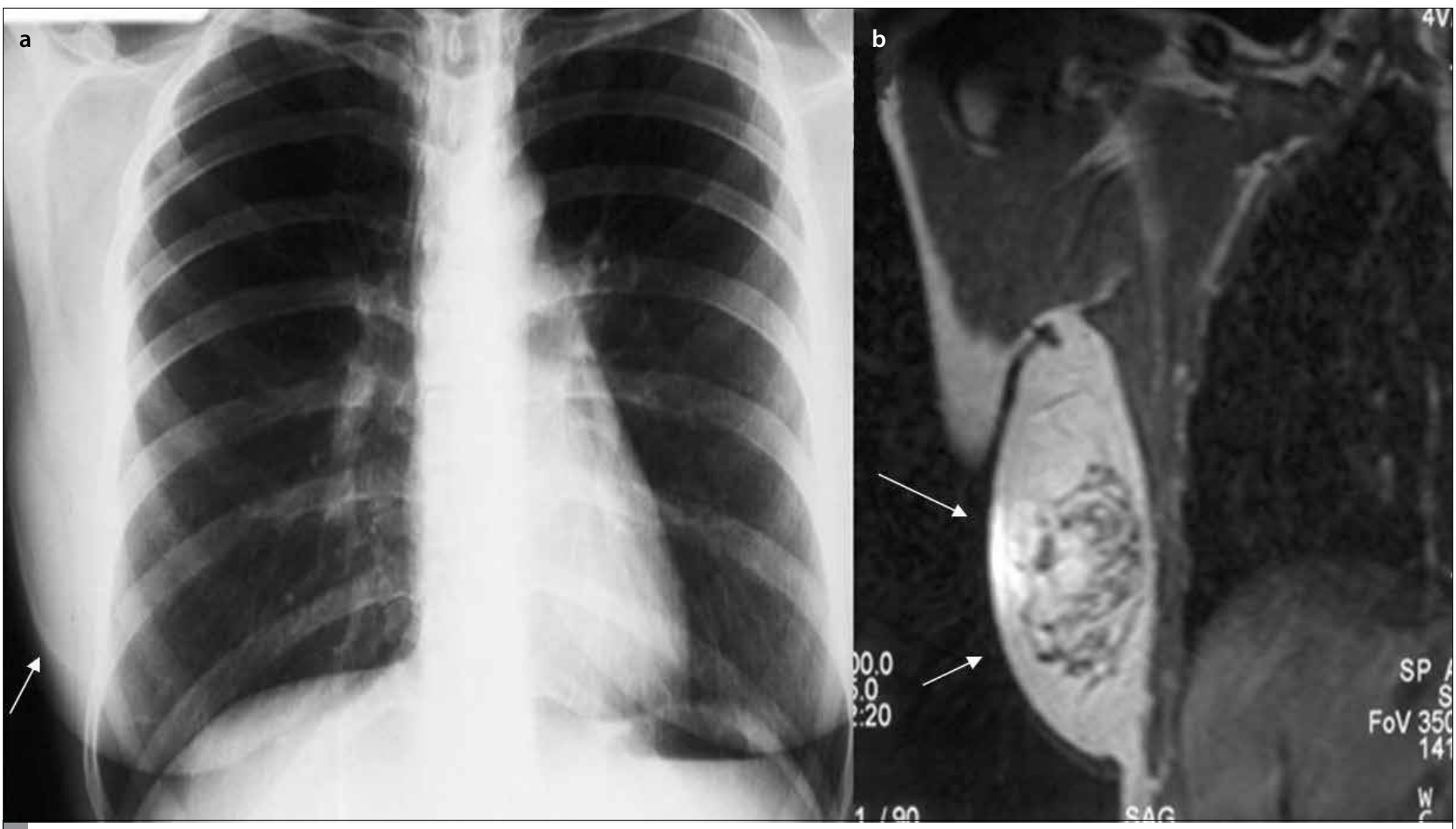

Figure 1. a, b. X-ray (a) and magnetic resonance imaging of the lesion on the right (b).

neous right infrascapular soft tissue mass (Figure $1 \mathrm{~b}$ ). It was measuring about $7.5 \times 7.5 \times 2 \mathrm{~cm}$. The mass had no capsule and was heterogeneous in nature, with a signal intensity similar to that of skeletal muscle.

The patient was operated on with the frontier diagnosis of bilateral soft tissue mass. The surgical approach included bilateral incisions made over the lesion with the arms positioned to expose the mass under general anesthesia.

A firm, rubbery, non-capsulated, tumor-like lesion with malignant appearance, measuring $10 \times 8 \mathrm{~cm}$ in diameter, was observed following the division of the latissimus dorsi muscle on the right side. The tumor was attached to the inferior angle of the scapula and was densely adherent to striated muscle. A frozen section of the incisional biopsy disclosed a benign tumor rich in collagen fibers. The tumor was totally excised by sharp and blunt dissection. The same procedure was performed on the mass located on the contralateral side.

Light microscopy revealed that these tumors were identical in appearance. Each of them was unencapsulated but had a smooth surface. There was collagenized connective tissue containing blood vessels, adipose tissue, and eosinophilic fragmented thick fibers with a beaded appearance and spherical particles that were characteristic of elastofibroma (Figure 2a). Verhoeff's elastic stain showed that these were elastic fibers (Figure $2 b$ ). Both masses were diagnosed as elastofibroma. The postoperative course was uneventful. The patient remains well and disease-free 6 months after surgery.

\section{DISCUSSION}

Elastofibroma dorsi is a rare connective tissue lesion (1). It is usually seen on the dorsal aspect of the body, but the most common site is the subscapular area of the chest wall $(1,6)$. When located between the latissimus dorsi and rhomboid muscles, it can not be recognized upon palpation.
The lateral chest wall, distal part of the olecranon, deltoid muscle, and ischium are other common sites. But, the greater omentum, stomach, orbita, tricuspid valve, mediastinum, axilla, rectum, breast, hands, and feet were also reported for its presence $(3,6)$.

Women are affected eight times more than men. The average age of patients is 70 years, but the age range in the largest series was 17-94 years (7).

The lesion is usually unilateral, but the frequency of bilateral occurrence was reported to be between $10-66 \%(3-5)$. The presence of a synchronous, new-growing lesion must almost always be investigated in a patient presented with a unilateral mass, like in our patient. Turna et al. (5) reported a bilateral EFD case in which one of the masses was not recognized at first admittance.

There is no radiologic modality that enables us to diagnose elastofibroma preoperatively. It might not be seen on chest X-ray or be only considered as an extrathoracal connective tissue mass. Ultrasonography usually reveals a hypoechoic linear array on an echogenic background. On the other hand, computed tomography and magnetic resonance imaging are more characteristic but not specific. Computed tomography usually reveals a non-homogenized connective tissue mass with interlaced strands of fat, which is similar to skeletal muscle in signal intensity. With these findings, the lesion can only be considered as a connective tissue mass. On MRI, a connective tissue mass could show alternating regions of high and intermediate signal intensity (8). On the other hand, in recent years, it was claimed that the definitive preoperative diagnosis could be achieved by fine-needle aspiration; thus, a more invasive means of obtaining a tissue diagnosis could be obviated (9). But, although Harigopal et al. (10) said that the possibility of a false-negative diagnosis was high due to the hypocellularity of the smears, they also claimed that the presence of autofluorescent elastic 

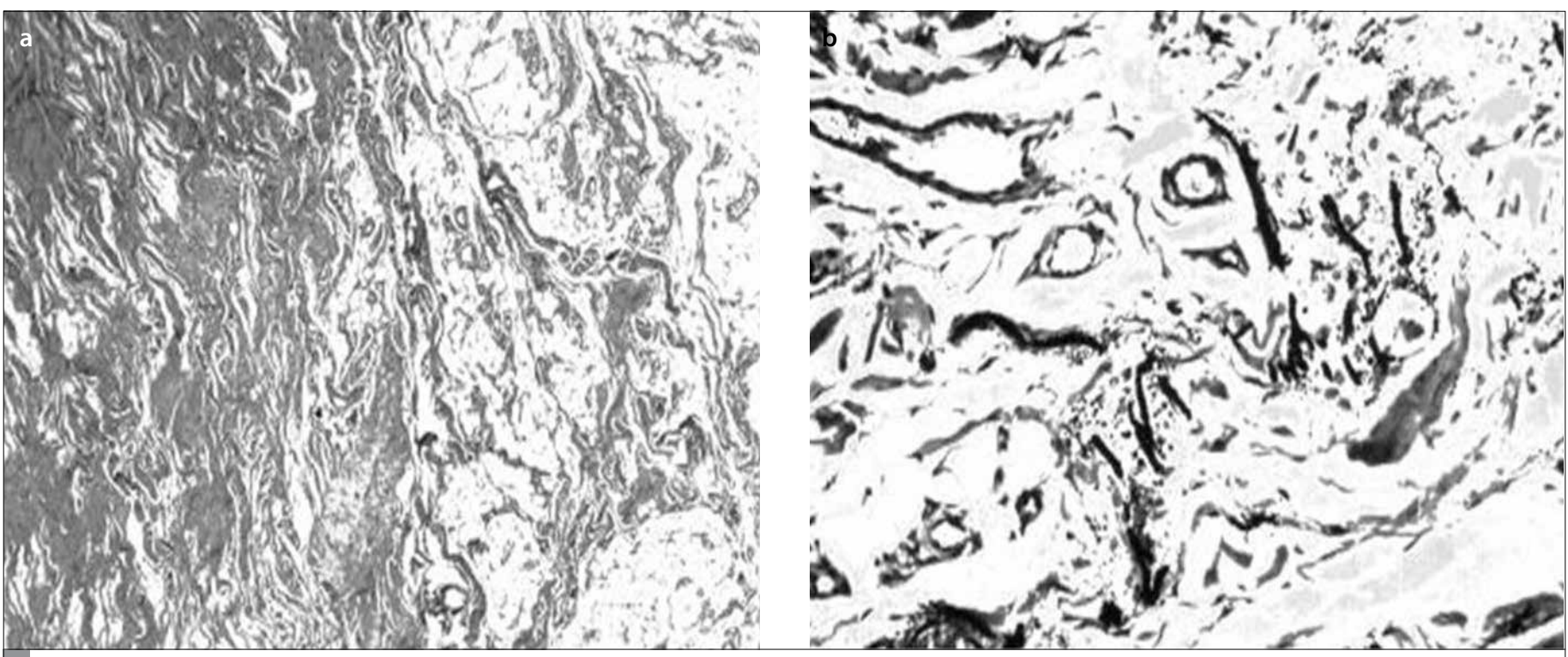

Figure 2. a, b. The lesion was composed of fibroelastic tissue, blood vessels, and fat (H\&E x 40) (a). Note the elastic fibers with a beaded appearance between the blood vessels in a collagenized background (H\&E x 400) (b).

fibers in a hypocellular aspirate, together with a high index of suspicion based on the clinical presentation of a firm mass in a typical location in an elderly person, should have suggested the possibility of EFD.

Macroscopically, the lesion is usually oval and unencapsulated with the margins ill defined. Its cut surface is tan-white and heterogeneous in appearance. Microscopically, the presence of fat, blood vessels, and elastic fibers with a typical beaded appearance in a collagenized connective tissue background is characteristic.

Although there are many theories about the etiopathogenesis, the origin of the lesion is still unknown (1). Since it is commonly seen in patients with a history of hard or heavy labor, Jarvi and Saxen (2) claimed that elastofibroma is caused by friction of the scapular apex to the chest wall. According to them, mechanical stress causes hypertrophy and degeneration in elastic tissues. Since our patient has been doing aerobic exercise for a long time and had bilateral masses, we also thought that mechanic stress might have a role in its pathogenesis. But, Stemmarmen and Stout (11) claimed that there must have been an abnormality in the elastic collagen to give rise to a mass. Barr (12) demonstrated that an enzymatic defect resulted in abnormal elastic tissue development. On the other hand, since the lesion can be seen in other parts of the body that are not under mechanical stress, genetic predisposition is discussed in its etiopathogenesis (6). As a result, it is still unclear that whether elastofibroma is a real neoplasm or only represents a reactive lesion that is characterized by the production of abnormal elastic and collagen fibers.

The treatment of choice is surgery (4). Although it is a benign process, it can adhere to the surrounding muscles and periosteum of the bones (5). So, it can mimic a malignant lesion intraoperatively. The mass in our case was also attached to the inner surface of the scapula. Thus, we think that in order to rule out malignancy, a frozen section is necessary to avoid radical surgery. The mass must be totally resected to decrease the risk of recurrence. But, there were cases in the literature who did not show any recurrences, although a partial resection could have been done. On the other hand, since some cases can show progressive enlargement and since some develop new lesions in other sites of the body, patients must be followed up clinically.

\section{CONCLUSION}

Although it is a benign lesion an EFD could really decrase quality of life due to pain. Although it is a rare thoracic wall disease of mostly women, it can be seen on other sites of the body. Its diagnose is simple and appropriate surgery may improve pain without recurrence.

Informed Consent: Written informed consent was obtained from patient who participated in this case.

Peer-review: Externally peer-reviewed.

Author contributions: Concept - M.T., I.C.K., I.I., L.M., S.D.; Design - M.T., I.C.K., I.I.G., L.M., S. D.; Supervision - M.T., I.C.K., I.I.G., L.M., S.D.; Resource -S.D., M.T., I.C.K.; Materials - S.D., M.T., I.C.K.; Data Collection\&/or Processing - M.T., I.I.G., L.M.; Analysis\&/or Interpretation - M.T., I.I.G., L.M.; Literature Search - M.T., I.I.G.; Writing - M.T., I.I.G.; Critical Reviews - L.M., S.D.

Conflict of Interest: No conflict of interest was declared by the authors.

Financial Disclosure: The authors declared that this study has received no financial support.

\section{REFERENCES}

1. Enzinger FM, Weiss SW. Benign fibrous tissue tumors. In: Soft tissue tumors, 4th ed. St. Louis: CV Mosby; 2001. p. 286-289.

2. Jarvi O, Saxen E. Elastofibroma dorse. Acta Pathol Microbiol Scand 1961; 144: 83-4.

3. Hsieh SC, Shih TT, Li YW: Bilateral elastofibroma dorsi. Two case reports. Clin Imaging 1999; 23: 47-50. [CrossRef]

4. Machens HG, Mechtersheimer R, Göhring U, Schlag PN. Bilateral elastofibroma dorsi. Ann Thorac Surg 1992; 54: 774-6. [CrossRef]

5. Turna A, Yılmaz MA, Urer N, Bedirhan MA, Gürses A. Bilateral elastofibroma Dorsi. Ann Thorac Surg 2002; 73: 630-2. [CrossRef]

6. Briccoli A, Casadei R, Di Renzo M, Favale L, Bacchini, Bertoni F. Elastofibroma dorsi. Surg Today 2000; 30: 147-52. [CrossRef]

7. Nagamine N, Nohara $\mathrm{Y}$, Ito E. Elastofibroma in Okinawa: A clinicopathologic study of 170 cases. Cancer 1982; 50: 1794-805.[CrossRef]

8. Soler R, Requejo I, Pombo F, Saez A. Elastofibroma dorsi: MR and CT findings. Eur J Radiol 1998; 27: 264-7. [CrossRef]

9. Mojica WD, Kuntzman T. Elastofibroma dorsi: elaboration of cytologic features and review of its pathogenesis. Diagn Cytopathol 2000; 23:393-6. [CrossRef]

10. Harigopal M, Seshan SV, DeLellis RA, Yankelevitz D, Vazquez M. Aspiration cytology of elastofibroma dorsi: case report with ultrastructural and immunocytochemical findings. Diagn Cytopathol 2002; 26: 310-3. [CrossRef]

11. Stemmerman GN, Stout AP. Elastofibroma dorsi. Am J Clin Pathol 1962; 27: 499-506.

12. Barr JR. Elastofibroma. Am J Clin Pathol 1966; 45: 679. 